\title{
Uma crítica à produção do TDAH e a administração de drogas para crianças
}

Bruna de Almeida Cruz. Instituto Federal do Pará.

Flávia Cristina Silveira Lemos. Universidade Federal do Pará.

Pedro Paulo Freire Piani. Universidade Federal do Pará.

Jacqueline Isaac Machado Brigagão. Universidade de São Paulo.

\begin{abstract}
Resumo
Este artigo tem como objetivo analisar a prática de realização de diagnósticos em seus efeitos de produção do TDAH como transtorno em crianças em período escolar e operar uma crítica aos encaminhamentos indiscriminados para psiquiatras, diante de acontecimentos que são transformados em queixa escolar e tomados como anormalidades. Entre os efeitos dessa prática muito recorrente na atualidade, está o crescimento exponencial da prescrição de drogas, tais como as anfetaminas para crianças, gerando graves problemas em suas vidas, o que deve ser alvo de uma problematização ética, política e social. Especificamente, a droga mais administrada nessa situação tem sido o metilfenidato e, no Brasil, ele tem sido amplamente vendido e utilizado nos casos avaliados como de desatenção e agitação psicomotora. Esse artigo é resultado de pesquisa de pós-graduação em psicologia em andamento e são apresentados, neste texto, resultados parciais do trabalho.
\end{abstract}

Palavras-chave: crianças; TDAH; escola; diagnóstico; medicalização.

\begin{abstract}
A critique of the production ADHD and the administration of drugs to children. This article aims to analyze the practice of diagnostics in their effects of producing ADHD as a disorder in children in school period and operate a criticism of indiscriminate referrals to psychiatrists the events that are taken as school problems and transformed into abnormalities. Among the effects of this very common practice today, is the exponential growth of prescription drugs, such as amphetamines to children, causing severe problems in their lives, which should be the subject of an ethical, political, and social problematization. Specifically, the more drug administered in this situation has been methylphenidate and in Brazil, it has been widely sold and used in cases assessed as inattention and restlessness. This article is the result of a graduate degree in psychology research, in progress and are presented in this text, partial results of the work.
\end{abstract}

Keywords: children; ADHD; school; diagnosis; medicalization.

\section{Resumen}

Una crítica de la producción TDAH y la administración de medicamentos a los niños. Este artículo tiene como objetivo analizar la práctica de realización de diagnósticos en sus efectos sobre la producción de TDAH como trastorno en niños en etapa escolar y operar una crítica de las referencias indiscriminadas a los psiquiatras de los acontecimientos que se toman como problemas escolares y son transformados en anomalías. Entre los efectos de esta práctica muy común hoy en día, es el crecimiento exponencial de los medicamentos con receta, como las anfetaminas a los niños, causando graves problemas en sus vidas, que deben ser objeto de una problematización ética, política y social. En concreto, más droga se administra de esta situación ha sido el metilfenidato y en Brasil, se ha vendido y utilizado en casos evaluados como la falta de atención y la inquietud. Este artículo es el resultado de un título de posgrado en investigación de la psicología, en curso y se presentan en este texto, los resultados parciales de la obra.

Palabras clave: niños; TDAH; escuela; diagnóstico; la medicalización. 
No século XX, emergiram os saberes da Psiquiatria Infantil e, paralelamente, a descrição de transtornos infantis como objetos de estudo e intervenção. O Manual Diagnóstico e Estatístico de Transtornos Mentais, da Associação Americana de Psiquiatria, dilatou-se ao longo de suas cinco edições, de 1952 a 2013: de 106 transtornos descritos na primeira edição, atingiu-se a marca de 300 categorias diagnósticas descritas na quinta e última publicação do manual. Nesse contexto, o uso de medicamentos psicotrópicos na infância é cada vez mais frequente e naturalizado, expandido a reboque da especulação e disseminação de novos transtornos.

Atualmente, um dos medicamentos psicoativos mais utilizados na infância é o cloridato de metilfenidato, indicado para tratar sintomas de pessoas diagnosticadas com transtorno de déficit de atenção com hiperatividade - TDAH ou narcolepsia (Brasil \& Belisário Filho, 2000). Esse fármaco é da família das anfetaminas e tem ação psicoestimulante. No Brasil, o consumo de metilfenidato cresceu exponencialmente, nos últimos anos. Calazans, Guerra, Kyrillos Neto, Pontes e Resende (2012) relatam que, de 2000 a 2004 , houve um aumento de $1024 \%$ nas vendas de caixas de metilfenidato e, entre 2004 e 2008, mais um aumento de $940 \%$. Em um boletim de 2012, a Agência Nacional de Vigilância Sanitária (ANVISA) aponta ainda que, entre 2009 e 2011, o consumo do medicamento continuou aumentando, especialmente no que se refere às doses diárias prescritas às crianças entre 06 e 16 anos (ANVISA, 2012).

Vale mencionar que boa parte dos encaminhamentos realizados para psiquiatras e neuropsiquiatras a fim de diagnosticar crianças é feito pelas escolas e, com isso, há uma produção massiva de crianças psicopatologizadas por meio de práticas que atravessam o contexto escolarizado de aprendizagem. As dificuldades em cumprir encomendas escolares no âmbito de processos de desenvolvimento e da aprendizagem são transformadas em queixas referentes aos estudantes, os quais apresentam o que alguns especialistas vão nomear como distúrbios e transtornos de aprendizagem (Souza, 2000).

Há uma utilização exacerbada de diagnósticos que se referem a problemas escolares, em especial, ligada ao que vem sendo considerado como transtornos de conduta, nos manuais médicos internacionais de classificação. O TDAH está na lista desses supostos transtornos e, de repente, parece que uma parte considerável de crianças abruptamente se tornou hiperativa e desatenta, recebendo laudos classificatórios de suas ações como transtornos a serem tratados com drogas psicotrópicas.

A prática de classificar o não aprender ou o ritmo e a maneira em que esse acontecimento ocorre ou não tem sido colocada em um campo que desliza entre explicações sociológicas, antropológicas, econômicas, nutricionais, psicológicas e neurobiológicas (Collares \& Moysés, 1996). Contudo, há grupos de pesquisadores e de profissionais que enfatizam um desses aspectos em detrimento dos outros, reduzindo tal acontecimento a um único fator, de forma causal, o que implica em criar lógicas deterministas e lineares de uma questão complexa.

Outro ponto a analisar é a relação entre uso de drogas chamadas lícitas e os processos de escolarização, que implica interrogar o lugar que os medicamentos ocupam nos modos de organização e produção de estudantes quietos e atentos, em contextos escolares. Ou seja, por que a queixa escolar é transformada em problema médico psiquiátrico a ser respondido pela prescrição de drogas, tais como as anfetaminas?

Tendo em vista essas problemáticas, este artigo pretende discutir as implicações entre o diagnóstico de TDAH e o uso indiscriminado de drogas psicotrópicas por crianças, na atualidade. Para tanto, sustentamo-nos em uma atitude crítica face à medicalização e aos modos contemporâneos de controle das infâncias.

\section{Metodologia}

Essa pesquisa utilizou a genealogia de Michel Foucault como metodologia, a partir da análise das práticas de saber e de poder, lançando mão de levantamento e revisão da literatura especializada no tema e da análise documental. Para Foucault (1979), a genealogia é um método histórico, que visa interrogar o presente, cotejando práticas que forjam acontecimentos inquietantes na sociedade atual. A genealogia, nesta pesquisa e, especialmente, nesse artigo, implica em pensar mecanismos de saber e poder em seus efeitos sobre os corpos de crianças encaminhadas por escolas aos médicos para a realização de diagnósticos sobre o TDAH de forma cada vez mais recorrente na atualidade, de acordo com a literatura levantada em pesquisa finalizada na pós-graduação em Psicologia, sociedade e saúde. Esse texto é parte do estudo realizado, trazendo apontamentos em formato de ensaio teóricotemático sobre o objeto encaminhamento de crianças diagnosticadas com TDAH aos serviços designados como de saúde. 
Foram levantados artigos nas bases de dados SCIELO, PEPSI, e LATINDEX como palavras-chave: TDAH, medicalização da infância, diagnósticos de crianças e adolescentes, patologização da infância, psiquiatrização da infância e diagnósticos em escolares. No presente texto, apresenta-se parte da discussão realizada a partir desse levantamento na pesquisa realizada na pós-graduação em Psicologia, sociedade e saúde, stricto sensu.

Os saberes das disciplinas, denominadas científicas, das leis e de diversos documentos são problematizados na articulação dos efeitos de poder que geram na regulação dos corpos. Assim, pressupõe-se a crítica histórica das práticas produtoras de objetos específicos e dos desdobramentos das mesmas em termos de relações de poder que operam nas intervenções profissionais, nas instituições, nas prescrições de tratamento e na criação de assujeitamentos dos corpos aos saberes que foram criados como efeitos das práticas sociais datadas (Foucault, 1979; Veyne, 1998).

Os documentos também são literatura e podem ser os artigos e as leis, as bulas e os manuais, os livros e as anamneses, entre outros. O recorte temporal e a escolha dos documentos é parte da preocupação na história e a demarcação das disputas de saber e de poder, ferramentas metodológicas importantes na genealogia (Foucault, 1979). Colocamos em discussão textos que compõem a crítica à medicalização da educação e da sociedade, dos clássicos internacionais às produções nacionais que questionam o nosso tempo, assim como textos contemporâneos que descrevem tecnicamente o diagnóstico e o tratamento do TDAH, entre outras produções acerca do uso de fármacos para o trato de transtornos mentais.

$\mathrm{Na}$ análise da literatura presente no artigo em tela, há, pois, uma tentativa de desnaturalizar a medicalização das dificuldades de escolarização, transformadas em anormalidade por meio do olhar diagnóstico. Mais especificamente, buscamos descrever criticamente e problematizar as práticas de saber e de poder operadas a partir de documentos que permeiam o diagnóstico de TDAH, na atualidade, tais como a literatura científica sobre o assunto e os manuais nos quais o processo diagnóstico se baseia.

Foucault, nos cursos O poder psiquiátrico (Foucault, 2006) e Os anormais (Foucault, 2002) problematiza como é realizada a construção social do diagnóstico a respeito do desenvolvimento e da aprendizagem enquanto categorias médico-psicológicas de crianças, na segunda metade do século XIX. A prática de poder opera a produção de um diagnóstico, de um rótulo, de encaminhamentos, atendimentos e prescrições. Quando falamos de medicalização e diagnóstico, estamos nos remetendo a um ato de poder sobre o corpo. Nesse aspecto, a genealogia permite desnaturalizar essa prática de poder e de saber sobre um corpo, que o coloca na condição de anormal a partir de um conjunto de critérios, construídos em uma época específica.

\section{Resultados}

Patto (2002) assinalou em um livro clássico A produção do fracasso escolar que nas primeiras décadas do século XX, no Brasil e em outros países, que a psicometria e o diagnóstico médico eram ferramentas criadas para deslocar as desigualdades sociais, econômicas, políticas, subjetivas e culturais para o âmbito individual, especialmente, pela patologização dos acontecimentos que começaram a ser denominados, à época, de problemas de aprendizagem. A busca de padronização do ensino a partir de um currículo nacional e a encomenda liberal meritocrática e de fomento à produção em série, no período, estava relacionada à racionalidade industrial moderna, ao tecnicismo cientificista, ao positivismo com modelos estatísticos, à medicalização e à psicologização da educação pela incorporação de teorias neurobiológicas e de medidas de supostas capacidades e habilidades psicológicas por meio de testes e escalas nomeadas como psicométricas.

As normas que eram estabelecidas para avaliar estudantes tinham relação com a construção de um modelo de aluno a ser alcançado e forjado pelas técnicas, metodologias, teorias, equipamentos e currículos pedagógicos, psicopedagógicos e biomédicos. $\mathrm{O}$ atraso, o ritmo lento, o ritmo acelerado, o corpo não disciplinado, a desatenção, a não concentração e tantas outras situações passaram por esquadrinhamentos variados: exames, testes, vigilâncias, encaminhamentos a especialistas, exclusões escolares e envio às classes especiais (Souza \& Machado, 1997). Trata-se de táticas de poder e de saber, operando pelo diagnóstico de crianças e adolescentes, via tecnologias de vigilâncias e exames disciplinares, avaliadores de condutas consideradas fora das normas tomadas como padrões de desempenho: cognitivo, psicomotor, neurofisiológico e afetivo-social.

O olhar clínico médico-psicológico da escola e do que era visto por ela como disruptivo e fora do modelo de aluno começa a gerar uma multidão de corpos patologizados pela educação e diagnosticados 
massivamente, recebendo rótulos e laudos. O equipamento escola passou a designar como anormalidade e doença o que a incomodava por sair dos esquadros a que estava acostumada a utilizar, a fim de regrar os corpos e as vidas de estudantes de forma extremamente descontextualizada, reducionista, causal linear e simplista (Machado, 1997).

Canguilhem (2012) analisou a construção da noção de anormalidade como avesso da norma, distinguindo os conceitos de patologia e de anormal. A doença para ele seria um acontecimento diferente da antinorma. Ou seja, o anormal era resultado da negação da norma, o que não necessariamente seria doença ou patologia, mas incomodaria muito mais pelo desvio de uma regra e de um padrão do que pela descrição e caracterização do que seria uma doença nos manuais médicos e dos critérios usados para catalogá-las. O olhar clínico, conforme Foucault (2008) emerge ligado ao nascimento da medicina como ciência clínica, no século XVIII. De acordo com Patto (1997), a Psicologia, na medida em que passa a figurar como contribuição nas escolas e nas famílias, nos hospitais e nas prisões, nas fábricas e nos exércitos, ao final do século XIX e início do século XX, se apropria de parte desse olhar clínico médico e o articula a um sistema de medidas estatístico, às explicações evolucionistas do desenvolvimento das crianças bem como às psicopatologias relacionadas às capacidades e desempenhos por um verniz psicofisiológico, neuropsicológico, psicomotor e afetivo-simbólico.

Segundo Araújo (2007), o predomínio do diagnóstico não ocorreu apenas na psicologia, mas teve grande abertura de mercado na psiquiatria, sobretudo, da segunda metade do século XX em diante (Castel, 1987). É possível afirmar que esta realidade alcançou um boom, na virada para o século XXI, na mesma medida em que os psiquiatras avançavam com suas práticas para fora dos hospitais psiquiátricos rumo às clínicas privadas. Meira (2012) destaca que boa parte dessa migração médica teve relação com a criação de novos medicamentos, entre eles, os psicotrópicos que passaram a ser indicados para crianças e adolescentes em função de queixas escolares.

A expansão impactante da prática de avaliação psicológica em diferentes contextos, bastante recorrente em psicodiagnósticos de crianças encaminhadas aos psicólogos pelas escolas, tem se colocado como uma questão preocupante no debate da psicologia escolar e da educação desde a década de setenta, no século XX. Nesse sentido, há críticas à formação na psicologia em moldes ainda muito clínicos e psicopatológicos e declarase que há uma encomenda crescente de adestramento e docilização das crianças em processo de escolarização, na sociedade contemporânea, acompanhada de pedidos de silenciamento das demandas outras que sustentam as práticas escolares e sociais.

Transtorno do déficit de atenção/hiperatividade (TDAH) é um termo utilizado para denominar um diagnóstico psiquiátrico, ou transtorno do neurodesenvolvimento. É comumente utilizado para nomear o quadro de pessoas - especialmente crianças e adolescentes - que apresentam, como características marcantes: desatenção, agitação motora e impulsividade. É também frequentemente descrito como uma desordem global do comportamento (Caliman, 2010), chamando a atenção de educadores, psicólogos, médicos e familiares.

Segundo Caliman (2008), o TDAH é um dos diagnósticos mais estudados no campo da neuropsiquiatria e; também considerado um dos mais controversos da atualidade. Sua tríade sintomatológica - déficit de atenção, hiperatividade e impulsividade - consiste em construtos que são amplamente disseminados atualmente, seja entre profissionais das áreas da saúde e da educação, seja pela população em geral. Uma das possíveis explicações para tão amplo conhecimento público acerca desses construtos é o próprio fato de terem sido reunidos na forma de uma síndrome.

Na década de 1980, Sucupira (1985) identificou que, na literatura americana, o TDAH era o distúrbio mais diagnosticado na infância e que, no Brasil, ganhou popularidade frequentemente associado ao fracasso escolar. Em 2012, o Sistema Nacional de Gerenciamento de Produtos Controlados sinaliza a mesma tendência, com elevado número de diagnósticos de TDAH, chegando a identificar sua prevalência em até $26,8 \%$ das crianças e adolescentes de algumas regiões deste país (ANVISA, 2012).

Essa disseminação também parece ter uma relação muito estreita com o potencial mercadológico que a transformação desses comportamentos em uma síndrome ou transtorno representa. Sobre isso, Caliman (2008) relata que, desde a década de 1980, antes mesmo de ter sido criado o diagnóstico de TDAH, o mundo já vivia intensa divulgação publicitária acerca do transtorno em questão e da Ritalina ou cloridrato de metilfenidato - na época, medicamento já disponível no mercado para tratamento. Boarini e Borges (2009) destacam ainda que, cerca de vinte anos antes de existir a classificação diagnóstica, já existia um medicamento destinado ao seu tratamento. 
Por mais que o TDAH como classificação de transtorno mental seja relativamente recente, a problemática com a qual está implicado não é de hoje, coincidindo com os primórdios da educação escolar. No início do século XIX, a principal categoria utilizada para as crianças com tais problemas era a idiotia, que não tinha caráter de doença mental (Carel \& Gyöffy, 2014). Caliman (2010) acrescenta que o idiota ou imbecil moral, sendo aquele que apresentava uma conduta desviante dos padrões normais de desenvolvimento cognitivo e moral, foi sendo convertido em hiperativo, ou portador de um transtorno neurológico. Assim, essas dificuldades escolares foram ganhando contorno de problema de saúde no final do século XIX e início do século XX, a partir do que se reconhece como as primeiras elaborações médicas acerca do comportamento de crianças com sintomas de desatenção, hiperatividade e impulsividade.

A história oficial do TDAH atribui frequentemente a George Still, pediatra inglês, a primeira definição de um quadro que combina déficit de atenção e hiperatividade, em estudo apresentado à Royal Society of Medicine, em 1902 (Boarini \& Borges, 2009). Segenreich e Mattos (2014) acrescentam que Still descrevia o problema como um déficit de controle da moral, considerando que as crianças estudadas apresentavam dificuldades de seguir regras a elas apresentadas. Segundo Caliman (2010), embora Still mencionasse a questão da falta de atenção em algumas de suas formulações explicativas, sua proposta não a enfatiza como elemento definidor do transtorno por ele descrito, tendo a hiperatividade e a impulsividade como aspectos centrais, que culminariam no problema de controle da moral.

Trinta anos mais tarde, Franz Kramer apresenta a hipótese de que o transtorno hipercinético infantil, como ele o denominou, era causado por uma espécie de lesão cerebral mínima (Segenreich \& Mattos, 2014). Eisemberg (2007) declara que a hipótese de lesão cerebral mínima se deveu a uma epidemia de encefalite que acometeu os Estados Unidos e o Canadá, após a Primeira Guerra Mundial. Como as crianças que se recuperavam da doença apresentavam comportamento caracterizado como hipercinético, foi suspeitada a existência de lesões cerebrais que causassem os sintomas, acreditando-se, por conta disso, que sintomas semelhantes observados em outras crianças seriam igualmente causados por lesão.

Após, constatou-se que não era possível identificar, a partir dos exames disponíveis na época, qualquer tipo de lesão na anatomia cerebral dessas crianças, sendo esta hipótese refutada e substituída pela noção de disfunção cerebral mínima, que estaria vinculada a um mau funcionamento das faculdades de atenção e controle inibitório no cérebro; em outras palavras, ligada a alterações funcionais em vias nervosas (Segenreich \& Mattos, 2014; Rohde, Barbosa, Tramontina, \& Polanczyk, 2000).

Caliman (2010) afirma, em relação a essas proposições, que o encontro entre a epidemia de encefalite letárgica e as questões de hiperatividade e desatenção não deve ser tomado como descoberta brilhante de um olhar científico apurado. Do ponto de vista científico, tais elaborações eram vagas e abrangentes demais, criando o que a autora chamou de "diagnósticos guarda-chuva". Sobre isso, Sucupira (1985) já afirmava que, embora impreciso e frágil, o conceito nosológico para a hiperatividade não só foi aceito, como ganhou relevo e popularidade, em virtude da clara necessidade de se medicalizar uma problemática social. A disfunção cerebral mínima, tendo tido grande aceitação na sociedade, perdurou como uma nomenclatura válida para o quadro, até que a Associação Americana de Psiquiatria (APA) organizou o conceito em seu manual diagnóstico, na tentativa de uniformizar o seu uso na comunidade científica sem, contudo, modificála conceitualmente de maneira significativa. Segundo Segenreich e Mattos (2014), é em 1968, na segunda edição do Manual Diagnóstico e Estatístico de Doenças Mentais (DSM II), que é inserida a "reação hipercinética da infância" como classificação nosológica, ainda com ênfase nos sintomas de hiperatividade.

É então na terceira edição do manual da APA (DSM III), de1980, que é classificado o quadro combinado de desatenção e hiperatividade, à guisa de substituição das nomenclaturas anteriores, sendo chamado de Transtorno do Déficit de Atenção com dois subtipos: com ou sem hiperatividade (Sucupira, 1985). Houve, ainda, uma revisão da terceira edição (DSM III-R), em 1987, na qual foi suprimida a classificação em subtipos, considerandose unitário o diagnóstico de TDAH (Segenreich \& Mattos, 2014). Nesse momento, a ênfase do diagnóstico a desatenção é considerada o elemento central do quadro, estando a hiperatividade presente ou não.

A maior parte das publicações recentes a respeito deste tema refere-se à quarta edição do manual da APA (DSM IV), de 1994, ou sua revisão (DSM IV-TR), de 2000, como versões mais atualizadas e, portanto, de uso corrente, tendo em vista que a quinta edição (DSM V) foi publicada apenas em 2013, com tradução para 
o português em 2014. A quarta edição, em relação à anterior, acrescenta que os sintomas do TDAH podem persistir na vida adulta, além de serem reassumidos os subtipos propostos no DSM III (Segenreich \& Mattos, 2014). A quarta edição do manual, transformando o TDAH em um problema não mais restrito à infância representa, assim, mais uma investida no sentido de abranger cada vez mais segmentos da população, na tentativa de explicar e resolver problemas a partir de uma perspectiva médica.

A quinta edição DSM, após doze anos de vigência da edição anterior, dá prosseguimento a este processo de patologização de diferentes questões da vida, de maneira crescente, não apenas no que diz respeito ao TDAH, dilatando também outros transtornos já descritos e criando novas classificações nosológicas. No que se refere ao TDAH, Segenreich e Mattos (2014), como bons disseminadores da história interna do transtorno, exaltam os anos de estudo que permitiram à quinta edição do DSM: modificar a idade máxima de início dos sintomas, de sete para doze anos; dissolver os subtipos do transtorno, considerando que diferentes sintomatologias de pessoas diagnosticadas com TDAH devem ser concebidas como diversas apresentações clínicas de uma mesma patologia; e, ainda, aponta como possibilidades de comorbidade alguns diagnósticos que antes excluíam a hipótese do TDAH, como, por exemplo, os transtornos do espectro autista. Essas modificações tornam o diagnóstico mais abrangente e aplicável a um maior número de pessoas.

Seja pela quarta, seja pela quinta edição, o uso do DSM como critério na produção do diagnóstico em questão é incontestável. No Brasil, no entanto, temos um outro referencial em uso neste processo, visto que a linguagem comum da assistência brasileira em saúde - o Sistema Único de Saúde (SUS) - é baseada na Classificação Internacional de Doenças, da Organização Mundial da Saúde (OMS), mais especificamente na sua décima edição (CID 10). Breinis (2014) considera que a CID 10, apesar de fornecer os códigos oficialmente utilizados pelo SUS, serve apenas para fins de nomenclatura, sendo o diagnóstico orientado pelo DSM V, na prática clínica. A esse respeito, Caliman e Domitrovic (2013) também comentam que, embora os códigos da CID sejam a linguagem comum nos procedimentos formais do SUS, os critérios diagnósticos do DSM adquiriram relevância, especialmente com a tradução e validação do SNAP IV, escala utilizada para o diagnóstico de TDAH e de Transtorno Opositor Desafiador (TOD). Já Segenreich e
Mattos (2014) afirmam que o DSM é predominantemente utilizado no campo da pesquisa, enquanto a CID é referência prioritária no campo assistencial.

Por mais similares e confundíveis que os DSMs e a CID 10, ainda em uso corrente, possam parecer "a olho nu", quando observamos atentamente os critérios diagnósticos apresentados por esses dois sistemas, podemos notar importante diferença no que diz respeito à abrangência de seus diagnósticos. Segundo Dumas (2010), embora ambos admitam sintomas muito semelhantes em seus critérios, o diagnóstico da CID 10 é mais restrito, na medida em que exige a presença de um número maior de sintomas em relação ao DSM IV, bem como sugere o descarte da hipótese de transtornos hipercinéticos, no caso de algumas comorbidades, tais como transtornos de humor ou de ansiedade, diferentemente do manual da APA. Quando é publicada a quinta edição do DSM, as diferenças tornam-se ainda mais acentuadas.

Eis algumas considerações a respeito do que se propõe na CID 10 para a compreensão dos famigerados problemas de atenção e hiperatividade. O que é chamado de TDAH no DSM é classificado, na CID 10, como "transtorno hipercinético", identificado pelos códigos iniciados com F90 (OMS, 2011). Nesta classificação, há quatro subtipos válidos: "perturbação da atividade e atenção" (F90.0), "transtorno de conduta hipercinética" (F90.1), "outros transtornos hipercinéticos" (F90.8) e "transtorno hipercinético, não especificado" (F90.9).

De acordo com a descrição da OMS (2011), a principal subdivisão proposta na CID 10 é feita de acordo com o preenchimento ou não de aspectos que caracterizam os "transtornos de conduta", seguindo-se os critérios da mesma publicação. Sendo assim, F90.0 caracteriza o preenchimento de critérios globais para transtorno hipercinético, sem que sejam satisfeitos os critérios para transtorno de conduta, enquanto F90.1 consiste no quadro que combina o preenchimento de ambos os critérios. Os demais códigos devem ser utilizados em casos de indefinição em relação aos dois primeiros.

No caso da CID 10, portanto, existe uma importante associação dos transtornos hipercinéticos às condições de transtornos de conduta. No DSM V, por sua vez, essas condições aparecem em duas sessões diferentes: "Transtornos do Neurodesenvolvimento" e "Transtornos Disruptivos, do Controle de Impulsos e da Conduta". Neste caso, o TDAH é mais claramente associado a "transtornos específicos da aprendizagem" 
e, diz-se, frequentemente se sobrepõe a transtornos "externalizantes" na infância, tais como o "transtorno opositor desafiante" e o "transtorno de conduta" (APA, 2014).

O diagnóstico do TDAH, ou de transtornos hipercinéticos, é fundamentalmente clínico. Isto quer dizer que o processo se baseia na observação direta da criança ou em sua descrição clínica por terceiros, a fim de verificar se preenche ou não os critérios apresentados nos sistemas classificatórios. Neste sentido, cumpre ao avaliador julgar se os critérios são atendidos ou não, contando com a colaboração de diferentes informantes, tais como os pais, a escola e a criança (Rohde et al., 2000). Segundo Breinis (2014), exames específicos não são necessários para o diagnóstico, sendo solicitados apenas para fins de diagnóstico diferencial ou de pesquisa.

Todavia, sabe-se que o desenvolvimento de exames de neuroimagem; entre outras tecnologias de visualização, contribuem para a afirmação de que o transtorno existe e pode ser comprovado como uma entidade clínica, endógena e cerebral (Caliman, 2010). Também não são infrequentes as pesquisas que buscam relacioná-lo a determinações genéticas, sendo esta uma das frentes de biologização do problema, contribuindo para o avanço do consumo de terapias medicamentosas, a exemplo de Breinis (2014), que (des)qualifica como injustas as críticas dirigidas à via farmacológica de tratamento. Tais críticas estão frequentemente associadas à defesa de perspectivas psicossociais para explicar a problemática, configurando resistência à hegemonia do discurso médico científico que constitui sua história oficial.

Diferentes histórias críticas sobre o TDAH contribuem para pensarmos a multideterminação da questão, entre as quais existem as que destacam a sua relação com interesses políticos de controle da delinquência e dos desvios da moral; outras enfatizam a influência da indústria farmacêutica no incentivo à sua investigação e produção como entidade nosológica; por fim, existem ainda estudos vinculados aos contornos contemporâneos da vida ocidental, marcada pelo excesso de informações, pelo imperativo do consumo e pela transitoriedade das relações. Nesse sentido, há quem afirme que o transtorno não existe, ou que sua conceituação é frágil; há também quem o trate como uma questão de determinação diversa às causas colocadas pelos estudos médicos; e há, ainda, os que defendem a ideia de que múltiplas causas se combinam na produção do transtorno, inclusive determinantes biológicos.
B. A. Cruz, F. C. S. Lemos, P. P. F. Piani, J. I. M. Brigagão

O diagnóstico é, portanto, perpassado por controvérsias, no que diz respeito à sua definição, etiologia, diagnóstico e tratamento. As polêmicas referentes ao uso do psicotrópico para controlar sintomas do TDAH também são inúmeras. Críticos da literatura especializada do TDAH, a partir da qual se tende a legitimá-lo como um transtorno neurológico consistentemente comprovado, está dividido desde os que questionam a inconsistência dos seus critérios diagnósticos até os que negam completamente a existência do transtorno (Caliman, 2010).

A falta de consenso acerca do diagnóstico e os efeitos colaterais, considerados nocivos, do medicamento, o qual é frequentemente utilizado, geram especulações sobre a validade e o custo dessa expansão do transtorno. Associado ao consumo crescente de metilfenidato, o TDAH é considerado um dos principais diagnósticos envolvidos nos chamados processos de farmacologização e medicalização da vida (Caliman \& Domitrovic, 2013).

Faraone e Bianchi (2013) chegam a afirmar que o TDAH é analisador ou bode expiatório de um processo mais amplo, supondo uma lógica de construção social que o transcende. As autoras argumentam que esse diagnóstico se sustenta tão fortemente como explicação para problemas de atenção e da atividade, por mais inconsistente e polêmico que seja, exatamente por recair predominantemente sobre o público infantil, população que ocupa um lugar central nas estratégias medicalizadoras. Sendo assim, entendemos que, por mais que seja perpassada por controvérsias, o uso dessa categoria diagnóstica provoca impactos na dinâmica social e na vida das pessoas diagnosticadas. Caliman (2013) argumenta que a mesma já vem modelando certas formas de cidadania, pautadas na crença de que os indivíduos com o transtorno merecem uma atenção especial na escola, por exemplo, afirmando-se como sujeitos de um direito que lhes cabe pela sua condição neurológica. Diante disso, Untoiglich (2013) aponta para sua faceta estigmatizante e seu potencial de segregação da pessoa diagnosticada, sugerindo que estes, além do consumo de psicotrópicos, seriam efeitos nocivos do uso inadvertido e generalizado do diagnóstico de TDAH.

Diante disso, consideramos pertinente discutir a complexidade da relação historicamente nutrida entre o diagnóstico de TDAH, como categoria que emerge em um contexto social medicalizado, e o crescimento do mercado de consumo de fármacos pelo público infantil, com a justificativa de responder a queixas escolares. 
A despeito de tamanha controvérsia perante o TDAH como categoria nosológica, vemos, como um dos efeitos da produção do transtorno, o surgimento de propostas terapêuticas para tratá-lo, abrindo-se um amplo mercado da saúde, dirigido às crianças e às escolas, de cunho medicalizante e reducionista dos acontecimentos em jogo, trazendo uma série de elementos éticos a ser alvo de problematização no que tange aos direitos de crianças e às práticas profissionais vigentes. A complexidade das práticas sociais e escolares, das histórias de vida de crianças e de suas singularidades bem como a crítica à naturalização dos interesses da indústria farmacêutica e de corporações profissionais e empresariais fica impedida de circular ou é produz pouca incidência política no deslocamento da vertente medicalizante dos corpos e da mercantilização dos desvios das normas, transformado em anormalidade a ser diagnostica e tratada com drogas designadas como lícitas.

Breinis (2014) e Rohde et al. (2000) afirmam que o tratamento do TDAH deve ter uma abordagem múltipla, operando intervenções psicossociais, educacionais e farmacológicas, bem como concordam que a intervenção medicamentosa mais eficaz consiste no uso de psicoestimulantes. A estratégia medicamentosa ganha importante destaque, por ser frequentemente eleita como recurso central na resolução do problema.

Embora Mattos, Rohde e Polanczyck (2012) afirmem que o TDAH é subtratado no Brasil, este país já é o segundo maior consumidor mundial do cloridato de metilfenidato, que é o psicoestimulante mais prescrito e consumido para o tratamento do transtorno. Calazans et al. (2012) relatam um aumento exacerbado no consumo do referido medicamento, indicando-o como efeito do aumento do número de casos de TDAH, com as revisões dos DSMs. Os autores caracterizam esse aumento como epidêmico, chamando atenção para a criação de novas epidemias psíquicas.

São prometidos como efeitos do uso desse psicofármaco: melhoria da atenção, o que supostamente auxiliaria na execução das atividades escolares. Para esta finalidade, o fármaco é comumente prescrito como medida supostamente eficaz, sendo a alternativa de primeira escolha no tratamento médico do TDAH. Todavia, Boarini e Borges (2009) relatam que a tão prometida eficácia no controle desses sintomas não necessariamente acarreta melhoras no aprendizado escolar, que costuma ser uma das questões envolvidas na queixa que leva à busca de tratamento para a criança.
Um dos achados da pesquisa relatada pelas autoras é que o estado da criança sob o efeito do medicamento pode aparentemente ser de maior quietude, mas estar ligado a certa apatia e mesmo à fixação da atenção em qualquer outra coisa que não a situação de aprendizagem que lhe é apresentada. Frente ao resultado da pesquisa, é importante ressaltar as dimensões: ética, econômica, social e política que estão em jogo no uso e prescrição desse medicamento; sobretudo, quando o mesmo tem sido indicado para crianças indiscriminadamente.

Sobre isso, Moysés (2012) afirma que o efeito de apatia é o que se chama de efeito Zumbi Like, descrito como ausência de pensamentos e sensações, o que caracteriza toxicidade do medicamento, sendo indicada a suspensão imediata do mesmo. Por isso, a autora assevera que a droga não é segura, como tanto afirmam os autores que trabalham para laboratórios farmacêuticos. Lista, ainda, alguns efeitos adversos do referido estimulante: sonolência ou insônia, alucinações, prejuízos na cognição, bem como efeitos no sistema cardiovascular, incluindo arritmia, hipertensão e parada cardíaca.

Itaborahy e Ortega (2013) realizaram um estudo sobre dez anos de publicações acerca do metilfenidato e apresentam também alguns efeitos colaterais do uso desse medicamento, relatados nessas publicações. Entre os mais frequentes, estão: dor de cabeça, redução do apetite e consequente perda de peso, insônia, dores abdominais e redução do crescimento. Entre os efeitos menos frequentes, elencam: dependência, aumento da irritabilidade em pacientes com TDAH, depressão e melancolia, piora dos sintomas de hiperatividade, náusea, taquicardia, risco de doenças cardiovasculares e hipertensão, aumento da ansiedade, potencial de abuso, prejuízo à região frontal do cérebro e, finalmente, dependência psicológica. Alguns desses efeitos são relatados, logo ao ser iniciado o uso do fármaco, enquanto outros são percebidos nos casos de uso crônico do medicamento.

Além dos estimulantes, outras categorias de substâncias psicoativas também vêm sendo utilizadas na infância, tais como antidepressivos, antipsicóticos e estabilizadores do humor. Brasil e Belisário Filho (2000) apresentam algumas considerações sobre o uso dessas substâncias e alguns de seus efeitos colaterais. Entre os antidepressivos, os autores destacam os tipos tricíclicos (ADT) e inibidores seletivos da recaptação de serotonina (ISRS). 
Os efeitos colaterais mais comuns, decorrentes do uso de ADT por crianças, são: boca seca, diplopia, constipação, sedação, tontura, náusea, insônia, ganho ou perda de peso, tremores de extremidades e palpitações. Também existem relatos de irritabilidade e inquietação, bem como taquicardia, alterações e reações sanguíneas e maior suscetibilidade a convulsões (Brasil \& Belisário Filho, 2000). Sobre os ISRS, os autores apontam os efeitos colaterais mais conhecidos na população jovem, entre os quais estão: cefaleia, náusea, anorexia, dor abdominal, tontura, sonolência, insônia, nervosismo, ansiedade, inquietação motora, sudoração excessiva e urticária. Em adição, apontam para relatos, tanto em adultos quanto em crianças de crises convulsivas, reações de mania em adolescentes, desinibição psicomotora e reações adversas de sangramentos espontâneos.

Ainda sobre uso de antidepressivos, Scivoletto e Tarelho (2002) defendem que os ISRS devem ser os antidepressivos de primeira escolha, enquanto os ADT devem ser utilizados em apenas alguns casos, em virtude de critérios de segurança, toxicidade e efeitos colaterais. Sobre isso, afirmam que os ADT apresentam risco de cardiotoxicidade e relatos de morte súbita, requerendo monitoramento cuidadoso. Em relação aos ISRS, afirmam que os efeitos colaterais mais frequentes são problemas gastrointestinais, náusea e distúrbios do sono.

Sobre os estabilizadores do humor, Brasil e Belisário Filho (2000) comentam efeitos colaterais o uso do lítio, da carbamazepina ou do valproato de sódio. Segundo os autores, os dois últimos fármacos não são aprovados, nos Estados Unidos, pela Food and Drug Administration (FDA), em virtude de seus efeitos adversos. Entre esses efeitos, destacam: leucopenia, plaquetopenia e mais raramente anemia aplástica. 0 valproato de sódio é caracterizado como hepatotóxico, especialmente para crianças mais jovens e, em mulheres é associado à obesidade e a ovário policístico. Sobre o uso do lítio, há queixas de hipotireoidismo e cardiotoxicidade como efeitos adversos.

O uso de antipsicóticos, tais como haloperidol, pimozide e risperidona, por sua vez, é comumente recomendado para diferentes tipos de demandas, sendo empregados para uma gama maior de sintomas no público infanto-juvenil, quando comparado ao público adulto. Entre os casos aos quais são prescritos esses fármacos, estão os de Síndrome de Tourette, TDAH, transtornos do sono, bem como casos de auto-lesão, agressividade ou irritabilidade (Brasil \& Belisário Filho, 2000).
Os autores afirmam que as reações adversas mais comumente relacionadas a esse tipo de medicamentos são efeitos neurológicos, tais como sedação, dellirium e convulsão, bem como cardiológicos, como, por exemplo, hipotensão e alterações no eletrocardiograma. Também apontam para efeitos de irritabilidade e disforia, ou tristeza, como efeitos que podem aparecer enquanto o fármaco estiver em uso.

Como relatado, alguns fármacos podem apresentar o efeito paradoxal de acentuar os sintomas contra os quais deveriam atuar. Existe uma gama notável de fatores patológicos que surgem em função do uso de alguns medicamentos psicotrópicos. Em alguns casos, o aparecimento desses efeitos motiva a suspensão do medicamento, mas, em outros, leva ao consumo combinado de outros fármacos a fim de controla-los. Desse modo, perde-se de vista o ponto que distingue quando o medicamento traz benefícios ao usuário de quando ele mesmo produz o que promete controlar.

Ainda assim, deparamo-nos com o crescente número de prescrições desses fármacos, acompanhado de um aumento epidêmico de diagnósticos de transtornos - mais especificamente, o TDAH - a o longo dos últimos anos. Entendemos que esse movimento paradoxal se relaciona às tramas de saber-poder que implicam os esforços de normalização das dificuldades escolares, pois os efeitos nocivos do uso desses medicamentos não são preocupantes o suficiente diante do potencial econômico e de normalização social que seu consumo representa.

\section{Considerações finais}

Finalizando, as críticas à prescrição e ao uso indiscriminado desses psicotrópicos vêm se tornando cada vez mais numerosas e vêm dialogando com as práticas de prescrição e consumo, tensionando os contornos que vinham tomando. Neste artigo, vimos que o TDAH, assim como outros diagnósticos atribuídos a crianças, por sua vinculação a uma lógica biologizante e medicalizante dos problemas educacionais, associase fortemente ao consumo de psicofármacos, tendo como efeito o controle e a reinserção das infâncias rebeldes e improdutivas nos circuitos considerados normais para o desenvolvimento das crianças e para sua escolarização, por meio da manipulação bioquímica dos corpos. Também analisamos que essa relação tem efeitos sobre a saúde das pessoas inseridas em tais circuitos de consumo, gerando inclusive prejuízos para o seu bem-estar e até mesmo para o seu desenvolvimento por meio de intensa psiquiatrização e patologização 
das existências, a partir de práticas de poder e saber entrecruzadas, nas políticas de atendimentos à saúde e educação de crianças e adolescentes.

Portanto, chamamos atenção para a importância de se pensar em estratégias críticas ao uso e prescrição indiscriminada de drogas para crianças, sobretudo, nesse artigo, analisamos o abuso de anfetaminas e alertamos para que haja um compromisso de inquietação e reflexão nas políticas educativas e de saúde para que seja formulada uma perspectiva de redução de danos na política sobre drogas para esses casos também em que há prescrição e encaminhamento indiscriminado de crianças para a realização de diagnósticos e recomendações de administração de psicotrópicos.

\section{Referências}

Agência Nacional de Vigilância Sanitária (2012, julho/dezembro). Prescrição e consumo de metilfenidato no Brasil: identificando riscos para o monitoramento e controle sanitário. Boletim de Farmacoepidemiologia do Sistema Nacional para Gerenciamento de Produtos Controlados, (2), pp.1-14. Recuperado de <http://portal.anvisa.gov. $\mathrm{br} / \mathrm{wps} / \mathrm{wcm} / \mathrm{connect} / \mathrm{c4038b004e996487ada1af8a610f4177/ \text {bole- }}$ tim_sngpc_2_2012+corrigido+2.pdf?MOD=AJPERES>

Araújo, M. F. (2007). Estratégias de diagnóstico e avaliação psicológica. Psicologia: Teoria e Prática, 9(2), 126-141. Recuperado de http:// pepsic.bvsalud.org/scielo.php?script=sci_arttext\&pid=S1516$-36872007000200008 \& \operatorname{lng}=e n \& t \operatorname{lng}=p t$

Associação Americana de Psiquiatria. (2014). Manual diagnóstico e estatístico de transtornos mentais ( $5^{\mathrm{a}}$ ed.). Porto Alegre: Artmed.

Boarini, M. L., \& Borges, R. F. (2009). Hiperatividade, higiene mental, psicotrópicos: enigmas da caixa de Pandora. Maringá: EDUEM.

Brasil, H. H. A., \& Belisário Filho, J. F. (2000). Psicofarmacoterapia. Revista Brasileira de Psiquiatria, São Paulo, 22(Suppl. 2), 42-47. doi: 10.1590/S1516-44462000000600012

Breinis, P. (2014). Transtorno do déficit de atenção na infância. Pediatria Moderna, 50(9), 388-396. Recuperado de http://www.moreirajr.com. $\mathrm{br} /$ revistas.asp? fase $=$ r003\&id_materia $=5887$

Calazans, R., Guerra, A., Kyrillos Neto, F., Pontes, S., \& Resende, M. S. (2012). Manifesto de São João Del Rei-Brasil - em prol de uma psicopatologia clínica. In R. Calazans \& F. Kyrillos Neto (Orgs.), Psicopatologia em debate: controvérsias sobre os DSMs (pp. 159173). Barbacena: EdUEMG.

Caliman, L.V. (2008). OTDAH: entre as funções, disfunções e otimização da atenção. Psicologia em Estudo, 13(3), 559-566. doi: 10.1590/ S1413-73722008000300017

Caliman, L. V. (2010). Notas sobre a história oficial do Transtorno do déficit de atenção/hiperatividade TDAH. Psicologia: Ciência e Profissão, 30(1), 46-61. doi: 10.1590/S1414-98932010000100005

Caliman, L. V. (2013). Os bio-diagnósticos na era das cidadanias biológicas. In C. A. L. Collares, M. A. A. Moysés, \& M. C. F. Ribeiro (Orgs.), Novas capturas, antigos diagnósticos na era dos transtornos (pp. 109-118). Campinas: Mercado das Letras.
Caliman, L.V., \& Domitrovic, N. (2013). Uma análise da dispensa pública do metilfenidato no Brasil: o caso do Espírito Santo. Physis - Revista de Saúde Coletiva,23(3), 879-902.

Canguilhem, G. (2012). O conhecimento da vida. Rio de Janeiro: Forense.

Carel, H., \& Gyöffy, G. (2014). Seen but not heard: children and epistemic injustice. The Lancet, 384(9950), 256-1257. doi: 10.1016/S01406736(14)61759-1

Castel, R. A (1987). A gestão de riscos: da antipsiquiatria à pós-psicanálise. Rio de Janeiro: Francisco Alves.

Collares, C. A. L., \& Moysés, M. A. A. (1996). Preconceitos no cotidiano escolar: ensino e medicalização. São Paulo: Cortez.

Eisemberg, L. (2007). Commentary with a historical perspective by a child psychiatrist: when "AHDH" was the "brain-damaged child". Journal of Child and Adolescent Psychopharmacology, 17(3), 279-283. doi: 10.1089/cap.2006.0139

Faraone, S., \& Bianchi, E. (2013). Medicalización de la infancia a través del análisis del transtorno por déficit de atención com hiperactividad (TDA/H) en Argentina: Usuários, psicofármacos y manuales de diagnóstico. In C. A. L. Collares, M. A. A. Moysés, \& M. C. F. Ribeiro (Orgs.), Novas capturas, antigos diagnósticos na era dos transtornos (pp. 93-107). Campinas: Mercado das Letras.

Foucault, M. (1979). Microfísica do poder. Rio de Janeiro: Graal.

Foucault, M. (2002). Os anormais. São Paulo: Martins Fontes.

Foucault, M. (2006). O poder psiquiátrico. São Paulo: Martins Fontes.

Foucault, M. (2008). Onascimento da clínica (6 $6^{\mathrm{a}}$ ed.). Rio de Janeiro: Forense.

Itaborahy, C., \& Ortega, F. (2013). O metifenidato no Brasil: uma década de publicações. Ciência \& Saúde Coletiva, 18(3), 803-816. https:// dx.doi.org/10.1590/S1413-81232013000300026

Machado, A. M. (1997). Relato de uma intervenção na escola pública. In Souza \& Machado (Orgs.), Psicologia escolar: em busca de novos rumos (pp. 87-100). São Paulo: Casa do Psicólogo.

Mattos, P., Rohde, L. A., \& Polanczyk, G.V. (2012). ADHD is undertreated in Brazil. Revista Brasileira de Psiquiatria, 34(4), 513-514. https:// dx.doi.org/10.1016/j.rbp.2012.04.002

Meira, M. E. M. (2012). Para uma crítica da medicalização na educação. Revista Semestral da Associação Brasileira de Psicologia Escolare Educacional, SP, 16(1), 135-142. doi: 10.1590/S1413-85572012000100014

Patto, M. H. S. (1997). Para uma crítica da razão psicométrica. Psicologia USP, 8(1), 47-62. doi: 10.1590/S0103-65641997000100004

Patto, M. H. S. (2002) A produção do fracasso escolar. (2ª ed.). São Paulo: Casa do Psicólogo.

Rohde, L.A., Barbosa, G., Tramontina, S., \& Polanczyk, G. (2000). Transtorno de déficit de atenção/hiperatividade. Revista Brasileira de Psiquiatria, 22(Suppl. 2), 7-11. doi: 10.1590/S1516-44462000000600003

Scivoletto, S., \& Tarelho, L.G. (2002). Depressão na infância e adolescência. Revista Brasileira de Medicina, 59(8), 555-557. Recuperado de http:// www.moreiraj.com.br/revistas.asp?id_materia=2054\&fase=imprime

Segenreich, D., \& Mattos, P. (2014). Contribuições dos "estudos de famílias" em TDAH - uma ferramenta útil para pesquisas sobre a etiologia do TDAH. Debates em Psiquiatria, 4(1), 42-50. Recuperado de http://www.abp.org.br/download/2014/RDP1.pdf

Souza, M. P. R. (2000). A queixa escolar na formação de psicólogos: desafios e perspectivas. In E. Tanamachi, M. Proença \& M. Rocha (Orgs.), Psicologia e Educação: desafios teóricos e práticos (pp. 105-142). São Paulo: Casa do Psicólogo. 
Souza, M. P. R., \& Machado, A. M. (1997). As crianças excluídas da escola: um alerta para a Psicologia. In M. P. R. Souza \& A. M. Machado (Orgs.), Psicologia escolar: em busca de novos rumos (pp. 35-50). São Paulo: Casa do Psicólogo.

Sucupira, A. C. S. L. (1985). Hiperatividade: doença ou rótulo? In C. A. L Collares \& M. A. A. Moysés (Orgs.), Caderno do CEDES 15 - Fracasso escolar - uma questão médica? (pp. 30-47). São Paulo: Cortez.
Untoiglich, G. (2013). Usos biopolíticos do suposto transtorno de déficit de atenção e hiperatividade: que lugar para o sofrimento psíquico na infância. In Novas capturas, antigos diagnósticos na era dos transtornos. Memórias do II Seminário Internacional Educação Medicalizada: Dislexia, TDAH e outros supostos transtornos (pp. 109-118). Campinas, SP: Mercado das Letras.

Veyne, P. (1998). Como se escreve a história. Brasília: UNB.

Bruna de Almeida Cruz, Mestre em Psicologia pela Universidade Federal do Pará, é Psicóloga Educacional no Instituto Federal do Pará (IFPA). Endereço para correspondência: Tv. Quintino Bocaiúva, 1249/ap. 602 Reduto - CEP: 66053-240. Belém, PA. E-mail: brunaacruz@gmail.com

Flávia Cristina Silveira Lemos, Doutora em História Cultural pela Universidade Estadual Paulista (UNESP), Pós-doutora em Psicologia Social pela Universidade Federal Fluminense (UFF), é Professora Associada I em Psicologia Social na Universidade Federal do Pará (UFPA) e Bolsista de produtividade em pesquisa CNPQ-PQ2. E-mail: flaviacslemos@gmail.com

Pedro Paulo Freire Piani, Doutor em Psicologia Social pela Pontíficia Universidade Católica/SP (PUC/SP), é Gerente de Ensino e Pesquisa do Complexo Hospitalar da Universidade Federal do Pará (UFPA). E-mail: pedropiani@yahoo.com.br

Jacqueline Isaac Machado Brigagão, Doutora em Psicologia pelo Instituto de Psicologia da Universidade de São Paulo (IPUSP), é Professora no curso de Obstetrícia da Escola de Artes Ciências e Humanidades da Universidade de São Paulo (EACH-USP). E-mail: jac@usp.br

Recebido em 06.Mar.15

Revisado em 27.Jul.16 Aceito em 06.Out.16 